\title{
REINIER ROZESTRATEN EM RIBEIRÃO PRETO: MEMÓRIAS E ENRAIZAMENTO DA PSICOLOGIA NO BRASIL
}

\author{
Reinier Rozestraten at Ribeirão Preto: Memories and Roots of Psychology in Brazil \\ Reinier Rozestraten en Ribeirão Preto: Memorias y Arraigamiento de la Psicología en Brasil \\ † REINIER Johannes Antonius Rozestraten \\ Josemar de Campos Maciel \\ Denise Fernándes VAsConcellos
}

\begin{abstract}
Resumo: O texto que segue é um tanto entrevista, outro tanto um relato apaixonado em primeira pessoa do professor Reinier Johannes Antonius Rozestraten, narrando seus anos em Ribeirão Preto. Ele começa um pouco antes, lembrando como e quando chegou ao Brasil e o que fez nos anos que antecederam à sua atividade em Ribeirão Preto (São Paulo), seguindo até depois da sua aposentadoria. A prosa é livre e resulta de diálogos transcritos e editados com o mínimo possível de interferências dos pesquisadores responsáveis. As entrevistas estavam sendo coletadas para um outro trabalho de pesquisa, agora impossível devido ao passamento do Professor Reinier, mas vêm juntar-se a uma justa homenagem a um importante consolidador e testemunha imortal da psicologia no Brasil.
\end{abstract}

Palavras-chave: História da Psicologia no Brasil; História oral; Memória e Narrativa.

\begin{abstract}
What follows is half an interview, half a passionate first-person report made by and with Professor Reinier Johannes Antonius Rozestraten, with the aim of remembering and telling his years at Ribeirão Preto (São Paulo, Brazil). He begins some time before, remembering how and when he arrived to Brazil, and what have been his first activities, and goes until more recent years, after his official retirement. Language is free and the whole text is a result of dialogues that were transcribed and edited with as few interferences as possible. The interviews were planned as part of another research project, but it is ended now, due to the death of Professor Reinier. Anyway, they constitute a very deserved homage to an important consolidator and immortal witness of brazilian psychology.
\end{abstract}

Keywords: History of Psychology in Brazil; Oral history; Memory and Narrative.

Resumen: El texto que sigue es un poco una entrevista, otro poco, un relato apasionado en primera persona del profesor Reinier Johannes Antonius Rozestraten, narrando sus años en Riberão Preto. Él comienza un poco antes, recordando cómo y cuándo llegó a Brasil y lo que hizo en los años que precedieron su actividad en Riberão Preto (San Pablo) siguiendo hasta después de su jubilación. La prosa es libre y es el resultado de diálogos transcritos y editados con un mínimo posible de interferencias de los investigadores responsables. Las entrevistas estaban siendo recolectadas para otro trabajo de investigación, ahora imposible debido al fallecimiento del Profesor Reinier, pero, se junta a un homenaje justo a un importante cimentador y testigo inmortal de la Psicología en Brasil.

Palabras-clave: Historia de la Psicología en Brasil, Historia oral, Memoria y Narración.

\section{Breve Nota Introdutória}

A solicitação do texto que segue coincidiu com uma iniciativa que envolvia, entre outras etapas, um trabalho de coleta de dados orais, com o objetivo de atingir ao mesmo tempo dois aspectos da comunicação: a narrativa histórica e o seu significado, para a plasmação de elementos de cultura local. Tratava-se, então, de um treinamento de alunos de um curso de graduação em psicologia. No campo do significado dos relatos, vai-se em busca de padrões de pensamento no campo da profissão e pesquisa em psicologia que sejam relevantes para uma coletividade de profissionais. Mas esses padrões deverão ser encontrados nas narrativas de indivíduos singulares pessoas cuja comunidade de referência considera como sendo aportadores de contribuições de relevo para a área. Trata-se de um trabalho de levantamento e discussão de modelos de desenvolvimento humano, cultural e social através da história de indivíduos singulares.

Acontece que o primeiro indivíduo entrevistado, mostrou paciência e disponibilidade absolutamente "franciscana", foi simplesmente Reinier Johannes Antonius Rozestraten. Trata-se de uma figura de inequívoca importância para a psicologia no Brasil, seja como realizador individual, pela significatividade de sua produção, seja como participante do processo sociopolítico da institucionalização e do enraizamento da psicologia, pela sua participação em diversas iniciativas que deram origem ao que hoje a psicologia no Brasil é tenta ser ou mesmo tenta não ser. 
Mas o "lugar" do trabalho feito não é apenas o Brasil em geral: a narrativa que segue tem um enraizamento específico no Estado do Mato Grosso do Sul, e uma comunidade específica de reflexão, a comunidade dos professores e acadêmicos da Universidade Católica Dom Bosco. A presença do Prof. Reinier na referida Universidade foi - e continuará sendo fundamental em vários aspectos. Aqui, como sempre em sua história, ele consolida caminhos seguros, além de ter efetivamente aberto novos, com o pioneirismo de sempre.

Os dados que seguem são todos obtidos a partir de um relato oral. Mas a sua disposição tem uma ambição maior do que trazer um relato de memória, um testamento intelectual que seja: trata-se de resgatar o que motivou a opção por um campo de atuação social, na narrativa de uma pessoa relevante para a plasmação e estabelecimento de uma profissão. Assim, importa pensar na recuperação de padrões, expectativas e representações do ser e do fazer do psicólogo, em um contexto. Noutras palavras, o leitor/a não tem, a seguir, eventuais "memórias" de alguém do passado, que construiu elementos de prática da profissão de psicólogo. Mais que isso, tem o resultado provisório de uma investigação, homenagem e provocação a quem quiser ler história da psicologia - e em seu contexto, quiser ler essa história encarnada no testemunho do trabalho de Reinier Rozestraten.

Em vários momentos do texto que segue poder-se-ão notar opções por termos mais simples, de comunicação comum, ao invés de uma linguagem mais técnica. São opções devidas ao próprio Professor Reinier, que revisou e corrigiu o presente trabalho até a sua finalização, antes de voltar para o seio de sua família, de onde se despediu da vida.

\section{Reinier Rozestraten: Memórias dos Anos de Ribeirão Preto}

Entre outras coisas, Reinier Rozestraten foi um dos iniciadores da Psicologia do Trânsito no Brasil. Esse início não acontece de modo fortuito, mas estende raízes numa série de opções e numa rica experiência humana. Alguns de seus elementos podem ser recuperados a partir dos anos que o Professor passou, em Ribeirão Preto, anos importantíssimos para a definição e consolidação de sua vocação - mas também para a psicologia do Brasil, como se verá.

A primeira iniciativa do relato sobre os 25 anos durante os quais o Professor Reinier Rozestraten trabalhou na Faculdade de Filosofia, Ciências e Letras de Ribeirão Preto (1970 a 1995), atende também ao pedido da então redatora da revista Paideia, Dra Zélia Biasoli Alves, em comemoração aos 50 anos de professor universitário.

No fim de 1969, Reinier trabalhava no CEUB Centro Universitário de Brasília, na então recém-fundada Faculdade de Filosofia, Ciências e Letras, ajudando na ini- ciação do Curso de Psicologia nas disciplinas de Psicologia Geral, História da Psicologia e Psicologia Experimental.

Tomou conhecimento, por uma antiga colega da UFMG - Universidade Federal de Minas Gerais, que trabalhava no CNPq - Centro Nacional de Pesquisas, que havia uma vaga para professor na Faculdade de Filosofia, Ciências e Letras de Ribeirão Preto. Em função disso, rumou num sábado para essa cidade e, com alguma dificuldade, achou o caminho pela Avenida do Café para a Faculdade de Filosofia. Na época, a referida Faculdade era constituída de apenas dois blocos. No acesso não havia asfalto.

O chefe do Departamento de Psicologia e Educação, André Jacquemin, andava ministrando seu famoso exame final sobre o Teste de Rorschach - um exame que durava o dia inteiro, e que despertava admiração e relatos aterrorizados dos alunos que eram suas "vítimas". Esperando encontrar um senhor grisalho com a imponência e o ar solene de um chefe de Departamento, Reinier encontrou um jovem risonho que o recebeu muito gentilmente. $\mathrm{O}$ professor Jacquemin, belga de origem, explicou, assim, que ele chegava em boa hora, pois seus colegas e compatriotas belgas que haviam colaborado como professores na fundação e estruturação do Departamento de Psicologia e Educação em troca de seu serviço militar, tinham acabado de voltar para seu país de origem. Havia, então, necessidade urgente de professores para várias disciplinas.

As coincidências entre o que André Jacquemin precisava e a colocação que o prof. Reinier e sua esposa procuravam, foram ficando cada vez mais evidentes. Em suas próprias palavras:

\footnotetext{
"Sou holandês de Haia,... é isso, vizinho do senhor e desses professores belgas que estiveram aqui. Trabalho atualmente, no Centro Universitário de Brasília, onde participei da criação de um Curso de Psicologia, na recém fundada Faculdade de Filosofia. Elaborei lá vários instrumentos para o treinamento em Psicologia Experimental”.
}

Prof. Jacquemin pediu então ao Prof.Reinier que falasse um pouco mais sobre sua vida, sobre sua vinda para o Brasil e também sobre o que vinha realizando profissionalmente.

"Formei-me sacerdote na ordem franciscana e escolhi vir para o Brasil para lecionar no Colégio Santo Antônio, em Belo Horizonte. Chegando ao Brasil em 1950, preparei-me para isso, cursando História Natural na Faculdade de Filosofia, Ciências e Letras da UFMG.

Já formado e trabalhando participei de um curso de Psicologia Experimental Comparada de Aprendizagem e Aplicação à Educação com o professor André Rey, colega de Jean Piaget, que veio para o Brasil a convite da Catedrática de Psicologia Educacional, Dra. Helena Antipoff, de quem fora colega de turma em Genebra no curso de Psicologia, ministrado pelo professor Edouard Claparède.

Rey era um renomado experimentalista e também um dos principais psicólogos clínicos da Europa. O curso foi ministrado no ISER (Instituto Superior de Educação Rural), 
porém ligado ao Departamento de Pedagogia da UFMG (não havia ainda, em 1956, curso universitário de Psicologia em Minas Gerais). O curso foi ministrado em francês e compreendia vários experimentos de aprendizagem e uma parte de clínica e seleção. Foi ministrado na Escola Normal Rural e na Fazenda do Rosário, criada por Dra. Helena para atender crianças órfãs e deficientes.

Esse curso foi o início de uma reviravolta na minha vida, pois, do meu contato com o professor André Rey, veio a sua indicação à Dra. Helena Antipoff para que eu continuasse seu trabalho, ministrando o mesmo conteúdo no curso de Pedagogia na Faculdade de Filosofia da UFMG.

Tornei-me assim, junto com prof. Pedro Parafita de Bessa, assistente da Dra Helena Antipoff, com a tarefa de ministrar Psicologia de Aprendizagem nos cursos de Pedagogia e no de Licenciatura, além de "Os Sistemas Nervoso e Endócrino e Os Órgãos de Sentido” no Curso de Pedagogia. Colaborei com meu colega, o professor Pedro Bessa, sociólogo que conseguiu alguma verba para poder comprar alguns aparelhos de Psicologia Experimental humana.

Participei da fundação da Sociedade Mineira de Psicologia (SMP), com o prof. Pedro Parafita de Bessa, seu primeiro presidente e também fundador do SOSP- Serviços de Orientação e Seleção Profissional, que funcionava como uma espécie de filial do ISOP- Instituto de Seleção e Orientação Profissional do Rio de Janeiro, fundado por Emílio Mira y Lopez, autor do teste Psicodiagnóstico Mio-Kinético (PMK). Professor Pedro também fundou o curso de psicologia e o Instituto de Psicologia na Faculdade de Filosofia da Universidade Católica em 1958. Foi o primeiro curso de psicologia em Minas Gerais. Ele me convidou para ministrar a Biologia Educacional e as Teorias de personalidade.

Em 1959 cursei "Psiquiatria e Higiene Mental", curso realizado na Secretaria da Saúde de Minas Gerais, participando também das demonstrações nos hospitais psiquiátricos de Belo Horizonte e de São Paulo, procurando preencher as lacunas na minha formação.

Nessa mesma época trabalhei no Instituto Pestalozzi, principalmente, a pedido da diretora, na aplicação do teste Terman Merrill em crianças deficientes mentais e orientando as professoras em relação ao ensino e à aprendizagem.

Desde 1953 também trabalhei na favela dos Marmiteiros, onde entendi, durante uma convivência de mais de cinco anos, que grande parte dos favelados é constituída por pessoas boas do interior que vêm para a cidade grande procurar uma vida melhor. Consegui fazer lá um salão paroquial que também servia de cineminha e uma caixa de água com tanques e duchas para eles.

Um trabalho que tive muito satisfação em realizar, em conseqüência de meu trabalho de capelão na Escola Normal Rural (1957), foi a fundação de um curso de Catequese por Correspondência, "O Catequista", que abrangia além do conteúdo religioso, uma orientação sobre o desenvolvimento e a aprendizagem da criança. O curso se espalhou pelo Brasil e também fora dele, em Angola, Uruguai e Argentina e em três anos alcançou 13.000 cursistas.

Em 1960, fui de férias para a Europa e assisti a meu primeiro Congresso de Psicologia, na Universidade de Milão, onde conheci o laboratório de Psicologia Experimental montado pelo falecido médico, aviador, psicólogo, experimentalista e franciscano Frei Gemelli, nessa universidade. Em diversas outras universidades, visitei laboratórios semelhantes. Isto reforçou minha convicção de que a psicologia não é apenas uma questão de fala, quadro e giz. Em Roma terminei as últimas aulas do curso de Catequista e tive maior contato com Frei Zavalonni, que estava tentando introduzir a Psicologia Experimental na Universidade e que vinha de um estágio feito sob supervisão de Carl Rogers. Aproveitei para fazer uma breve psicoterapia "Centrada no Cliente". Em Genebra tive o prazer de reencontrar meu mestre André Rey.

No início de 1962, ao voltar para o Brasil, fui convidado por Dom Serafim, então Reitor, para substituir o Prof. Pedro Bessa na direção do Instituto de Psicologia e participei de estudos do projeto de Lei sobre a Psicologia (lei 4.119). Pedi e obtive de Dom Serafim a construção de um novo andar na Universidade Católica, para laboratórios de Psicologia Experimental e de Psicofisiologia, bem como de salas para Psicoterapia, Dinâmica de Grupo, Psicodrama, Orientação e Seleção Profissional. Introduzi a História da Psicologia e pouco tempo depois fui convidado pelo Diretor do Instituto de Psicologia da PUC do Rio de Janeiro, padre Antônio Benkö, para participar de uma seleção de operários no Rio de Janeiro, São Paulo e Belo Horizonte, para a Usina Ferro e Aço de Vitória. Aceitei o convite e fiz estágio com Pe. Antônio Benkö sobre a entrevista e os testes a serem aplicados. Por intermédio de Dom Serafim, obtivemos as seleções da Shell, Petrobrás e Companhia do Vale do Rio Doce.

A verba advinda dessa seleção foi o embrião para a criação do SIPUC - Serviços do Instituto de Psicologia da Pontifícia Universidade Católica em Minas Gerais. Naquele tempo os cursos de psicologia eram ministrados principalmente por professores de diversas áreas: médicos, pedagogos, psiquiatras, biólogos, sociólogos e estatísticos.

Quanto à bibliografia, não havia então, nas livrarias de Belo Horizonte, mais de 100 livros de psicologia, o que fazia com que os professores traduzissem do francês, inglês, espanhol, alemão e holandês o que julgassem útil para seus cursos. Montamos por isso uma sala apenas para a venda de apostilas, pois havia bem poucos livros-texto, o que não me impediu de fundar a biblioteca do Instituto de Psicologia com várias doações, inclusive grande parte da biblioteca do já então falecido Emilio Mira y Lopez, doada por sua viúva, a Sra. Alice Galland de Mira. Tive também o privilégio de aprender o PMK com D. Alice no ISOP, num curso particular. Vim a ensinar o teste depois, a muitos estudantes; entre eles conheci Ângela Inês, que veio a ser minha esposa em 1967, depois que deixei o ministério e obtive a minha secularização.

Depois da promulgação da Lei dos Psicólogos, o professor Pedro Bessa fundou o Departamento de Psicologia na UFMG e convidou-me para ministrar as disciplinas de Psicologia Experimental, Psicologia do Adolescente e Psicofisiologia. Conheci lá também o prof. Pierre Weil com quem fiz o curso em Dinâmica de Grupo Triádico junto com Anne Ancelin Schutzenberg de Paris.

Foi a época da aprovação e promulgação da Lei que regulamentava a profissão de psicólogo. Conforme essa Lei, aqueles que já trabalhavam há cinco anos ou mais em psicologia, puderam adquirir sua carteira de Psicólogo, o que regulamentou minha atuação e de vários outros professores, inclusive do prof. Pedro Bessa. 
No ano de 1968, com a intensificação dos movimentos revolucionários universitários em Belo Horizonte, preferi sair dali, pois tinha a sensação de que tudo o que havia sido construído seria implodido.

Trabalhei então, por quase um ano, em Salvador no Instituto de Psicologia da Bahia, sob a direção de Irmão Dubois, psicólogo que estagiara na França, com seleção de motoristas e que, aqui no Brasil também realizava seleção e orientação de profissionais.

Em seguida, a convite de uns amigos ex-alunos de psicologia da UFMG, fomos para Brasília onde, como já disse no início, trabalho hoje".

Professor Jacquemin que, com algumas perguntas e interrupções, escutava pacientemente, declarou que na Faculdade de Filosofia de Ribeirão Preto havia lugar para Reinier, na História da Psicologia, Psicologia Geral, Psicofísica e Psicologia Sensorial Experimental, bem como para sua esposa, nas áreas do teste PMK, Aconselhamento Psicológico e Orientação Profissional.

Ficou acertado que em fevereiro do ano seguinte, em 1970, o Professor Reinier e sua esposa, Professora Ângela Inês, estariam em Ribeirão para iniciarem o trabalho naquela Faculdade. No entanto, um fato inesperado modificou esses planos: alguns dias antes do Natal, Prof. Reinier viajou de carro de Brasília para Belo Horizonte onde já estavam Ângela Inês e seu primeiro filho, Artur. Viajava à noite num fusca quando, por volta de Paracatu, dois burros, cada um de um lado da estrada fecharam seu caminho. Reinier tentou passar entre eles, mas o que estava do lado direito entrou pelo pára-brisa e acertou o lado direito de seu rosto. Com o impacto ele desmaiou e não soube explicar exatamente o que aconteceu - o fusca foi depois encontrado perto de um rio.

Sem saber como, segundo o relato de outras pessoas, ele teria ido até a estrada e dali feito sinal para uma caminhoneta que levava pessoas para o velório de um tio. Reinier estava todo ensangüentado e eles, a princípio, se assustaram muito pensando que ele seria o falecido tio. Sentado no espaço de carga, pela roupa molhada de sangue concluiu que devia ter acontecido um acidente. Encontraram o médico que trabalhou durante duas horas, tirando caquinhos de vidro do seu rosto. Foi, então, transportado para o hospital Sarah Kubitschek, em Belo Horizonte, onde sofreu uma cirurgia na mandíbula em que os dentes de baixo foram costurados aos de cima, deixando apenas lugar para um canudinho, para se alimentar. Estava também com diplopia; o olho direito virado completamente para dentro. No entanto, graças aos bons cuidados de Ângela encaminhando-o para outro oftalmologista, não costuraram suas pálpebras - essa teria sido a proposta do profissional do hospital. Seis meses de ginástica ocular fizeram o olho voltar para seu lugar.

Esse acidente impediu-o de começar as aulas na data combinada e assim ficou, inicialmente, ajudando o prof. Luiz de Oliveira na disciplina de Análise Experimental do Comportamento. O Prof.Oliveira estudara com o prof.
Fred Keller, colega de Skinner, num curso de AEC organizado por Carolina Martuscelli Bori, na USP, em São Paulo, alguns anos antes.

Depois de alguns meses, liberado da amarração dos dentes, pode começar com os cursos: Psicologia Geral, na qual seguiu os dois volumes de "Elementos de Psicologia" de Krech e Crutchfield, por meio de questionários discutidos em grupo; História da Psicologia, baseado na literatura da Universidade de Nijmegen da Holanda; Psicofísica e Psicologia Sensorial, estudadas com a ajuda dos livros de Muller, de Paul Fraisse do laboratório de Psicologia Experimental da Sorbonne e o clássico "Psicologia Experimental” de Woodworth e Schlossberg.

Pouco depois da mudança para Ribeirão Preto, Reinier e sua esposa sentiram haver encontrado o lugar certo para viver; o trabalho era satisfatório, havia tranqüilidade e equilíbrio financeiro. Depois de algumas andanças conseguiram uma casa confortável, vizinha à Universidade. Nesses anos nasceram mais três filhos: Annie, Hugo e Flávia, que freqüentaram a Escola de Vita et Pax, fundada por beneditinas holandesas. Foi de grande importância o apoio que receberam do prof. Dr. Geraldo Garcia Duarte, diretor da Faculdade, inclusive ajudando a encontrar moradia na cidade.

Aos poucos Reinier construiu uma apostila para o trabalho com a Psicofísica, passando também a organizar melhor seu experimento, construindo kits que continham uma série de agulhas em centigramas, um paquímetro transformado em estesiômetro, uma escala de envelopes de pesos crescentes e uma série de pesos em potinhos de yakult pintados de preto, para a determinação do Limiar Absoluto e do Limiar Diferencial. Acrescentou depois um aparelho para aplicar o método do Erro Médio à ilusão de Muller-Lyer.

No fim do ano de 1970 ou começo de 1971, a turma de Ângela, $5^{\circ}$ ano, liderada por Ricardo Gorayeb, lançou a idéia de uma Sociedade de Psicologia. Como Reinier havia sido o segundo presidente da Sociedade Mineira de Psicologia, solicitaram-lhe que aceitasse a presidência da nova Sociedade. Com alguma experiência, de posse dos Estatutos da SPMG para servir de modelo e, mais ainda, com a certeza de que João Cláudio Todorov aceitaria ser o vice-presidente, Reinier aceitou, de bom grado, a incumbência.

Depois de algumas reuniões com pessoas interessadas na fundação da Sociedade de Psicologia de Ribeirão Preto (SPRP), foi formada a primeira chapa da diretoria. Além dos já mencionados presidente e primeiro vice-presidente, ficaram como segundo vice-presidente Ângela Inês Simões Rozestraten, como secretários Ricardo Gorayeb e Tereza Moreira Leite e, como tesoureiros Lino de Macedo e Luiz Marcellino de Oliveira.

Lançaram, com a ajuda de Ricardo Gorayeb, um humilde hectografado Boletim da SPRP, produzido em casa. No entanto, a grande idéia que tornou a SPRP conhecida veio de João Cláudio Todorov que, com sua experiência 
adquirida nos EUA, propôs que se firmasse o compromisso de realizar Reuniões Anuais (RA) da Sociedade. Foi deliberado que a última semana de outubro seria um bom período. Assim, em outubro de 1971, aconteceu a primeira Reunião Anual, num antigo salão de cinema com a presença de cerca de 150 participantes, grande parte do Instituto de Psicologia da USP de São Paulo. Estava lançada a semente. De ano para ano, o número de participantes veio crescendo. Milhares de psicólogos já apresentaram suas idéias de muitas maneiras nas mais de 35 RAs.

A primeira diretoria ficou em exercício por três anos, de 1971 a 1973. Reinier permaneceu na presidência por mais um mandato, 1990, quando lançou a idéia de transformar a SPRP em SBP - Sociedade Brasileira de Psicologia, uma vez que não havia uma Sociedade ou Associação ativa em nível nacional. A idéia foi aceita a partir de então. Ele ainda ficou mais duas vezes como vice-presidente com os presidentes Ricardo Gorayeb, em 1991, e Carolina Martuscelli Bori, em 1992-1993.

Como presidente da SPRP foi, em 1972, chamado pelo prof. Aroldo Rodrigues, psicólogo social, para uma reunião na PUC/RJ, à qual convidara um grupo de psicólogos em posição de liderança na psicologia do Brasil. O motivo era algo semelhante ao atual movimento em torno à proposta de Lei do Ato Médico: um movimento de psiquiatras tentando monopolizar o exercício da psicoterapia, tirando-a das mãos dos psicólogos. Foi aí que nasceu a premência de desencadear um movimento em prol da criação de um Conselho Federal de Psicologia (CFP). Arrigo Angelini tomou a frente deste movimento, convocando reuniões em Brasília e organizando uma eleição de membros do futuro Conselho Federal de Psicologia. Reinier ficou como suplente de um psicólogo membro que era Deputado Federal, Clovis Stenzel, que praticamente nunca poderia estar presente nas reuniões por suas tarefas políticas, o que fez com que Reinier participasse de todas as reuniões iniciais (entre 1973-1975) quando foram criados os Estatutos do CFP, e para o qual Reinier desenvolveu um pré-projeto versando sobre as eleições.

As primeiras reuniões se realizaram numa sala do Ministério de Trabalho (na realidade, mais que sala era um depósito de móveis usados). Pouco depois, foi providenciada uma sede para o CFP: uma pequena sala com um grande espelho na parede, para dar a impressão de ser maior do que era na realidade. Nessa sala, meio ilusória, sob a presidência de Arrigo Angelini, foram criados os estatutos do CFP, bem como a divisão dos diversos CRPs - Conselhos Regionais de Psicologia. Assim, a psicologia brasileira passou a ter um órgão representativo oficial e uma organização nas diversas regiões do país. Posteriormente, de 1977 a 1979, Reinier ainda fez parte da Diretoria do CRP-06, o que se repetiu em 1989.

Tanto Reinier quanto Ângela fizeram inscrição para o mestrado em São Paulo, no IPUSP - Instituto de Psicologia da USP. Porém, como ele já estava inscrito para o doutorado na Faculdade de Filosofia e Ciências
Humanas da UFMG, foi aconselhado a fazer diretamente o doutorado.

João Cláudio Todorov, então recentemente retornado dos Estados Unidos com seu PhD, possibilitou que Reinier assistisse seu curso de pós-graduação sobre "A Punição", na Faculdade de Medicina, prontificando-se a ser seu orientador. Combinando a Psicologia Sensorial, os procedimentos do Behaviorismo e a orientação segura de João Cláudio, montaram um projeto sobre Estímulos Discriminativos e Estímulos Aversivos.

João Cláudio tinha seu laboratório instalado na Faculdade de Medicina (Fisiologia) e o trabalho com os animais tinha que ser diário, não perdoando nem Natal nem Ano Novo. Os resultados, no entanto, compensaram e a punição mostrou ser pouco eficiente quando voltaram os estímulos discriminativos do reforço.

Finalmente, no dia 13 de novembro de 1971, Reinier defendeu seu doutoramento na Faculdade de Filosofia da UFMG, em Belo Horizonte, tendo na banca além de seu orientador, os doutores Carolina Martuscelli Bori, Maria Auxiliadora Brasil, Célio Garcia e Ruy Miranda, sendo aprovado com distinção.

Um antigo caderno testemunha que, no mesmo ano de 1971, a partir de abril, o agora Doutor Reinier começou a trabalhar com monitores, entre os quais: Regina Helena Sacoman, Regina Inês Martins e Doralice Marques, orientando os diversos experimentos de Psicologia Sensorial. Por não existir ainda o recurso da fotocópia, os textos de Garrett e Fraisse foram copiados por estêncil. O trabalho de monitoria continuou durante o segundo semestre daquele ano.

Foi no ano 1973 que o Departamento de Psicologia e Educação recebeu a notícia de que, na Faculdade de Educação de Araraquara, um professor argentino ia dar cursos sobre a teoria de Jean Piaget. Tratava-se do médico Antonio Maria Battro que, depois de seu doutorado com Paul Fraisse na Sorbonne, ficou trabalhando três anos com Piaget no Institut Jean Jacques Rousseau em Genebra. Durante os anos 1973 e 1974, deu cursos sobre o Pensamento de Jean Piaget e sobre o Pensamento da Criança na fase Pré-operatória, em Araraquara. De quinze em quinze dias o grupo, Lino de Macedo, duas colegas pedagogas e o professor Renier rumavam para Araraquara, para assistir suas aulas. Para Lino de Macedo foi a construção de uma linha de trabalho para sua vida, começando com a tradução do "Diccionario de Epistemologia Genetica” de Battro e tornando-se, aos poucos, um dos maiores especialistas em Piaget e um grande difusor do Construtivismo no Brasil.

Battro introduziu também um assunto que interessava a Piaget: a percepção em grande escala, percepção de praças e edifícios, em comparação com a percepção em pequena escala, no laboratório. Sob sua orientação, iniciouse em Ribeirão Preto, uma série de pesquisas em campo aberto: a bisecção, a trisecção, a construção de paralelos e a percepção de ângulos à maior distância. 
As primeiras pesquisas de que Reinier participou foram sobre paralelas e eqüidistâncias, realizadas num magnífico campo de pólo do Jóquei Club de Ribeirão Preto que, embora muito distante do campus, foi negociado como empréstimo, por não haver, naquela época, espaço no campus da USP.

Seguiram-se trabalhos com avaliação de ângulos, de bi- e tri-seção de distâncias, trabalhos com ilusões de Oppel-Kundt e de Ponzo, realizadas em laboratório e campo aberto muitas com amostras de crianças menores.

Anualmente realizava-se um Simpósio Brasileiro de Psicologia Cognitiva dos trabalhos realizados. O primeiro aconteceu no Instituto de Psicologia da USP, em São Paulo, em 1974, onde Reinier apresentou os "Primeiros Resultados do Estudo da Ilusão de Oppel-Kundt em Campo Aberto".

Desenvolveram-se trabalhos com crianças e houve a ajuda de vários estudantes que vieram, inclusive aos domingos, realizar os experimentos em campo aberto e também tomar conta das crianças. Naquele tempo, os alunos ainda consideravam um privilégio colaborar nas pesquisas dos professores.

Foram colaboradores entusiastas: José Aparecido da Silva, Antonio dos Santos Andrade, Maria Auxiliadora da Silva, Lígia de Almeida Resende Ebner, Lúcia Márcia Mairi e Maria Aparecida Crepaldi que, com a ajuda de bolsas da FAPESP, deram sua colaboração e apresentaram os trabalhos nos Simpósios de Psicologia Cognitiva e na Reunião Anual da SPRP.

No II Simpósio, que aconteceu em Araraquara, Reinier apresentou um "Estudo de Simetria em Crianças de 6 a 11 anos", verificando que o conceito de simetria somente se instala no fim do oitavo ano.

No III Simpósio, realizado em Ribeirão Preto, apresentou, com a colaboração de vários estudantes e a presença do prof. Paul Fraisse, do Laboratório de Psicologia Experimental da Sorbonne, vários trabalhos sobre a Legibilidade das placas de trânsito. Os resultados tratavam de estudos psicofísicos de tipos de letras, de distanciamento entre letras, palavras e letras no laboratório, estudo de contraste ótimo entre fundo e figura. Os melhores contrastes eram de branco sobre fundo azul ou verde e de amarelo reflexivo sobre preto. Foi uma época de boa produção.

Foi dessa maneira que, a partir da psicofísica aplicada à percepção de grandes espaços, Reinier descobriu sua aplicabilidade para o trânsito e começou a entrar nessa área - pois é no trânsito que se encontra a situação na qual todos os usuários estão, continuamente, no grande espaço das vias e ambientes.

Naquela época Reinier conheceu o trabalho de Witkin com o "rod and frame test" e seu "embedded figures testEFT" distinguindo pessoas que têm dificuldade de descobrir figuras-alvo num ambiente complexo, os chamados "dependentes do campo visual”, e pessoas que fazem isto com certa facilidade, os "independentes do campo visual" e as conseqüências para sua personalidade, o que poderia ser aplicado na psicologia do trânsito.

Os trabalhos com tri-seção resultaram numa apresentação no $1^{\circ}$ Seminário de Ergonomia pelo ISOP (Instituto de Seleção e Orientação Profissional) no Rio de Janeiro em 1974, organizado por Franco Lo Presti Seminério, do trabalho "Alguns efeitos da percepção de distâncias em campo aberto sobre a confiabilidade do operador humano". O elogiado trabalho explicou que os freqüentes acidentes de trânsito na ultrapassagem poderiam ter suas causas em duas ilusões: a sub-estimação da distância para com o carro imediatamente à frente e a super-estimação da distância ao carro que vem em sentido contrário. Em 1976, Reinier ganhou o prêmio Emílio Mira e Lopez com a monografia "Dois estudos experimentais sobre a percepção visual humana no laboratório e no campo aberto".

O trabalho com paralelos feito no campo de pólo resultou num artigo em conjunto com A. Battro e S. di Pierro Netto na revista Perception: "Riemannian geometries of variable curvature in visual space: visual alleys, horopters and triangles in big open fields", sobre a percepção visual em grandes campos abertos. O artigo foi então considerado por Battro como o melhor que tinha orientado e escrito. No mesmo ano Reinier apresentou um trabalho sobre "Uma catástrofe visual: a reversão da ilusão de Oppel-Kundt em campo aberto" " A visual catastrophe: the reversal of the Oppel-Kundt Illussion in open field") no XXI Congrès Internationale de Psychologie em Paris como um exemplo da teoria de Catástrofe, conforme Battro. Em distâncias maiores e com crianças menores, a ilusão se inverteu.

Com a necessidade de contar com um laboratório ao ar livre mais perto da faculdade e também com a experiência já adquirida, foi montado um projeto, incluindo problemas teóricos e práticos de percepção de placas nas rodovias. Esse projeto trouxe um auxílio financeiro do CNPq, no ano de 1976, além de seis bolsas: quatro de iniciação e duas de aperfeiçoamento. $\mathrm{O}$ auxílio do $\mathrm{CNPq}$ permitiu a construção bastante trabalhosa de um campo de 300 x 35m, principalmente nos meses de chuva, que obrigaram à construção de um sistema de escoamento por baixo do campo.

Em 1977, o IV Simpósio Brasileiro de Psicologia Cognitiva foi realizado em Ribeirão Preto. Reinier apresentou os trabalhos "Avaliação de Frações e Múltiplos de uma distância padrão no laboratório e no campo aberto" e "Distanciamento entre letras, palavras e frases nas mensagens escritas nas placas rodoviárias". Ele e seus colaboradores tinham descoberto que estas distâncias nos padrões do DNER foram feitos no laboratório a seis metros e que a 40 metros eram necessários espaços maiores. Para isto tiveram que construir um taquistoscópio, que poderia ser usado em campo aberto, funcionando com menos de um segundo, pois os disponíveis somente funcionavam no laboratório. 
Foi mais ou menos naquele ano que um professor de Oftalmologia da Faculdade de Medicina, Dr. Harley Edison A. Bicas veio apresentar o professor Jack Loomis da Universidade de Califórnia, Santa Bárbara, oferecendo um estágio em Psicologia Experimental e Psicofísica naquela universidade. Uma vez que, à época, Reinier estava na chefia do departamento, não pôde aceitar pessoalmente a proposta. Encaminhou então, o bolsista José Aparecido da Silva, seu colaborador em pesquisas e em problemas matemáticos. Ele já havia feito seu mestrado em Psicologia experimental no IPUSP, sob a orientação de Lino de Macedo, pois naquele tempo a FFCL de Ribeirão Preto ainda não tinha pós-graduação. José Aparecido soube aproveitar de modo excelente esse estágio na Santa Bárbara, entrando em contato com eminentes psicofísicos americanos, publicando bastante e tornando-se conhecido mesmo na International Society for Psychophysics e na Psychonomic Society. Além disso, na sua volta, defendeu seu doutoramento ocupando em seguida diversos cargos administrativos, não apenas na FFCLRP, mas também no Campus da USP de Ribeirão Preto e substituindo Reinier já antes de sua aposentadoria.

De $1^{\circ}$ a 3 de junho de 1978, Reinier fez o Concurso de Livre Docência na FFCLRP, com a defesa da tese: "Estudos psicofísicos da percepção visual espacial em pequena e grande escala" e mais quatro provas, inclusive uma prática. Ao ser aprovado, obteve o título de professor Livre Docente em Percepção e Psicofísica.

Entre os anos 1970 e 1979, ainda fez parte de algumas bancas: de mestrado de José Aparecida da Silva, e dos doutorados de Paul Stephaneck, José Fernando Bitencourt Lomônaco, Luiz de Oliveira e Elenice Aparecida de Moraes Ferrari; além da banca de concurso de Livre Docência de André Albin Jacquemin.

Tomou conhecimento dos trabalhos do Laboratório de Psicologia da Conduta (Laboratoire de Psychologie de la Conduite) na França e, com o apoio do prof. Wisner, conseguiu lá um estágio. Nesse estágio, de pós-doutorado, trabalhou com o estilo perceptivo de Witkin, que foi aceito pelo diretor do laboratório M. Chich e pelo orientador, prof. Jacques Leplat, do INETOP, participando também nas aulas e discussões de trabalhos pelos alunos do mesmo. Utilizou bastante os testes: Rod and Frame Test original e reduzido, o Group Embedded Figures Test e o $3 D$-Embedded figures test de Williams. Foram aplicados testes em mais de 600 pessoas, grande parte recrutas e profissionais da Empresa de Correios e Telégrafos (PTT). Trabalhos sobre o assunto foram publicados nos Arquivos Brasileiros de Psicologia.

Quase no fim do estágio teve contato com o livro de David Shinar, "Psychology on the road", que deu outro conceito à Psicologia de Trânsito, mais do que a avaliação do motorista por meio de testes, como estava sendo praticada no Brasil. Esse novo conceito enfatizava a pesquisa do comportamento dos usuários, em situações comuns e em acidentes.
Voltou então ao Brasil com uma boa bagagem intelectual e separatas dos trabalhos do Laboratoire, com a idéia de fazer algo para promover a pesquisa na Psicologia do Trânsito, retribuindo, dessa forma, com algo para o Brasil, que lhe dera essa oportunidade de estágio.

Em 1981, foi designado pelo CFP para formar e presidir a Comissão Especial de Estudo do Exame Psicológico do Motorista. A Comissão contava ainda com os membros Efraim Bocalandro e José Augusto Della Coleta. Juntos realizaram uma pesquisa sobre os testes usados no Brasil nos diversos DETRANs (Departamentos de Trânsito), no Brasil e em outros países. Tiveram apenas seis meses para concluir tudo. É bom observar, a título de comparação, que o Grupo de Estudo dos Testes em Viena teve o tempo de 1981 até 1997 para só então apresentar o resultado no Congresso de Brunschweig. O Brasil sempre tem mais pressa.

Trabalhou de 1982 a 1984, na UFU - Universidade Federal de Uberlândia. Essa oportunidade surgiu porque Reinier, como professor da USP, tinha o direito de ficar, por algum tempo, em outra universidade e, como a FFCLRP estava com problemas em relação ao governo de estado, com o pagamento de seus professores, optou por passar esse tempo em Uberlândia.

Em Uberlândia, formou um Núcleo de Pesquisa em Psicologia do Trânsito, organizou um curso de pós-graduação lato sensu nessa mesma área e fundou também a revista Psicologia e Trânsito que foi editada apenas até o terceiro número, não tendo tido continuidade depois que o prof. Reinier saiu de Uberlândia. A universidade, além de editar a revista, editou também um "Catálogo de Pesquisas em Psicologia de Trânsito", que já havia sido elaborado em Ribeirão Preto.

Nos anos oitenta, foram realizados diversos Congressos de Psicologia do Trânsito: o primeiro em Porto Alegre (RS), em 1981; o segundo em Uberlândia (MG), em 1983, com a presença do prof. Michel Neboit da França e de D.Alice Galland de Mira do Rio de Janeiro; o terceiro em São Paulo (SP), em 1985, na Assembléia Legislativa; o quarto no Rio de Janeiro (RJ); e o quinto em Goiânia (GO), em 1989. Em quase todos, prof. Reinier ministrou cursos ou apresentou trabalhos. Além disso, ministrou cursos de Psicologia do Trânsito em muitos Departamentos Estaduais de Trânsito e em algumas universidades. O sexto Congresso somente se realizaria tempos depois, em Campo Grande (MS), na UCDB, no ano de 2004.

Em 1983, participou da Comissão de Elaboração dos Estatutos da futura ABERGO (Associação Brasileira de Ergonomia), da qual foi eleito vice-presidente e, três anos depois, presidente, organizando o I Congresso Latinoamericano de Ergonomia e o II Seminário Brasileiro de Ergonomia, no Centro de Convenções Rebouças em São Paulo, em dezembro de 1987.

De volta da UFU à FFCLRP submeteu-se a concurso para Professor Adjunto em Psicofísica e Percepção e foi aprovado. No entanto, o laboratório estava ocupado com 
outras pesquisas, levando-o a dedicar-se mais à divulgação de uma nova idéia de Psicologia do Trânsito, cujo principal objetivo baseava-se na humanização e no comportamento seguro no trânsito, e não mais nos testes.

Com essa nova visão, participou do I EDUTRAN organizado por um grande idealista da Educação para o Trânsito, Homero Henrique Rangel, um dos diretores do DNER (Departamento Nacional de Estradas de Rodagem), que percorrera o país em busca de adesão das universidades para a Educação para o Trânsito. Porém, não contou com o apoio do Ministro da Educação que nem se dignou a comparecer, mandando um representante. Desde então, até os dias de hoje, o governo federal continuou nada ou pouco fazendo para a Educação para o Trânsito, e até mesmo para obras de infra-estrutura ou desenho logístico.

Em 1987, as Faculdades Metropolitanas Unidas (FMU), de São Paulo, organizaram um curso de Pós-Graduação Lato Sensu Multidisciplinar de Trânsito que foi realizado com a ajuda de vários professores; além de Reinier, Raquel Alves dos Santos e Edda Augusta Quirino Simões. O projeto desse curso serviu alguns anos depois, para montar outros cursos multidisciplinares. No mesmo ano de 1987, o professor Reinier recebeu um convite de Dra. Geraldina Porto Witter para escrever um capítulo sobre a aprendizagem do trânsito para o livro "Psicologia da Aprendizagem: Áreas de Aplicação”, que resultou no seu sétimo capítulo intitulado: "Aprendizagem e Comportamento no Trânsito".

No final daquele ano foi aberta uma vaga para professor titular na USP e Reinier submeteu-se ao concurso, versando sobre a Metodologia da Psicologia do Trânsito incluindo a metodologia ergonômica. Foi aprovado como Professor Titular de Psicofísica, Percepção e Psicologia do Trânsito. Foi nesse mesmo ano que se realizou o I Congresso Latino-Americano da ABERGO, do qual era presidente. Infelizmente ocorreu também a separação do casal Reinier e Ângela, que mantiveram, no entanto, relações amistosas e os laços de família.

Em 1988, editou o livro "Psicologia do Trânsito: Conceitos e Processos Básicos”, pela EPU/EDUSP (Editora Pedagógica Universitária/ Editora da USP), livro que até hoje está sendo usado em cursos de Psicologia do Trânsito, que ainda é bastante citado em dissertações e teses da mesma área, e que ajudou a dar uma outra direção ao objeto da Psicologia do Trânsito no Brasil. Logo depois, aposentou-se continuando, no entanto, a prestar sua contribuição no Curso de Pós-Graduação em Psicobiologia, com disciplinas como: Fatores Perceptivos no Trânsito, Psicologia Ecológica, Percepção e Arte e Teorias de Percepção.

De 1992 a 1994, ministrou o Curso de Pós-graduação em História da Educação na UNAERP. Nos períodos de férias aceitou, na qualidade de doutor, ser responsável pelo Curso Multidisciplinar de Educação para o Trânsito (Pós-Graduação Lato Sensu), montado pela Profa. Maria Solange Felix Pereira, na então FUCMT (Faculdades
Unidas Católicas de Mato Grosso), nos moldes do Curso Multidisciplinar das FMU.

Participou em 1993, do Congresso da Abramet, em São Paulo, onde apresentou diversos trabalhos e durante o qual foi convidado para organizar um curso Multidisciplinar de Trânsito na UFPA (Universidade Federal do Pará), o que veio a acontecer em 1995, atuando na qualidade de professor visitante.

Em 1995, deixou Ribeirão Preto, ficando em seu lugar, o prof. José Aparecido da Silva que o substituiu com excelência, garantindo não só a continuação dos trabalhos que havia iniciado, como também a implementação de inúmeras melhorias na FFCLRP.

Depois de sua aposentadoria, foi Marina Massimi que se responsabilizou pela História da Psicologia, dando um desenvolvimento extraordinário a essa disciplina, publicando vários livros sobre o desenvolvimento da Psicologia no Brasil.

É com saudade que Reinier se lembra da sua convivência com seu colega Paul Stephaneck com o qual, durante anos, dividiu a sala e os interesses na pesquisa.

De 1995 até hoje, 2007, o prof. Reinier continua a construção de sua carreira profissional, mas devido ao volume de atividades e à restrição desse artigo a apenas uma etapa de sua vida, deixaremos as demais realizações para serem citadas em outros trabalhos.

\section{Produção de Reinier Johannes Antonius Rozestraten no Período de 1970 a 1995}

\section{Conferências e Cursos}

Novas perspectivas para o psicólogo do trânsito (1994). Palestra proferida no plenário do Conselho Nacional de Trânsito (CONTRAN) em Brasília pela ANPSITRAN 29/11/1994.

Formas de atuação do psicólogo junto ao Sistema de Trânsito Brasileiro (1994). In: I Simpósio Brasileiro de Psicologia do Trânsito - ANPSITRAN, Guarujá, SP.

Psicologia do trânsito: abrindo novos horizontes (1994). I Simpósio Brasileiro de Psicologia do Trânsito ANPSITRAN, Guarujá, SP.

Os sinais de trânsito e o comportamento seguro: comunicação viária (1994). In: I Simpósio de Segurança Viária, 65 anos de DER, DER/SP, Guarulhos, SP.

As fases psicogênicas do comportamento no trânsito (1992). In: Simpósio Volvo: Segurança de Trânsito e Jornalismo, Curitiba, PR.

Sinais de trânsito e comportamento (1992). In: I Congresso Panamericano de Questões e Desafios de Sinalização, Curitiba, PR.

Cursos de psicologia de trânsito: Ribeirão Preto SPRP, DETRANs de Curitiba, Campo Grande, Belo Horizonte, Florianópolis, Goiânia, Vitória (DNER-UFES), Rio de Janeiro (DNER), Fortaleza, São Paulo e Santos 1980-92. 
Curso: "Psicologia do Trânsito" (1993). Batalhão da Polícia Rodoviária de Minas Gerais, Belo Horizonte, 16 a 18 de junho de 1993.

Curso: "Psicologia do Trânsito e problemas profissionais" (1993). CRP 02, Recife, 29, 30 de julho de1993.

Curso: "Psicologia do Trânsito e trabalho do Psicólogo no DETRAN” (1993). DETRAN/PB, João Pessoa, 2 a 4 de agosto de 1993.

A Psicologia do Trânsito e Jornalismo (1993). Depto. de Psicologia, Univ. Cat. de Santos 13/05/1993.

Psicologia do Trânsito (1993). Depto. de Psicologia na Semana de psicologia, Universidade de Presidente Prudente SP, 06/05/1993.

Psicologia e Educação para o Trânsito (1993). DETRAN/ AL, Maceió 11/08/1993.

A Psicologia do Trânsito e Jornalismo (1993). Depto. de Psicologia, Univ. Cat. de Santos 13/05/1993.

Psicologia do Trânsito (1993). Depto. de Psicologia na Semana de psicologia, Universidade de Presidente Prudente SP, 06/05/1993.

Psicologia e Educação para o Trânsito (1993). DETRAN/ AL, Maceió 11 / 08 /1993.

Curso de Pós-Graduação lato sensu (1987-1989). Coordenação: Curso Multidisciplinar de Trânsito: disciplina Psicologia do Trânsito, Faculdades Metropolitanas Unidas FMU, São Paulo.

Curso de Pós-Graduação lato sensu (1992-1993). Coordenação: Curso Multidisciplinar de Trânsito, Faculdades Unidas Católicas de Mato Grosso do Sul FUCMAT Campo Grande MS. Disciplinas:

- Psicologia do Trânsito;

- Psicopedagogia de Trânsito nas escolas de primeiro e segundo graus.

Pós-Graduação stricto sensu (1985-92). Programa de Psicobiologia, FFCLRP-USP Disciplinas: Tópicos especiais: Fatores perceptivos no comportamento de trânsito; Psicologia Ecológica: Pesquisa e Aplicação.

A Segurança no Trânsito e os acidentes (1989). Palestra para III SIPAT INTEGRADA do Campus da USP/RP e HCRP.

Curso no Programa de Engenharia de Tráfego - Escola Politécnica - USP.

Disciplinas: O fator humano no trânsito, 1989; A Psicologia aplicada ao tráfego, 1990-91; A psicopedagogia do Trânsito, 1992.

A demografia dos idosos no Brasil (1991). SESC, Escola Aberta 3a Idade, Rib. Preto e para grupos de pastoral da 3a Idade na Catedral, nas Igrejas S. José e N. Sra de Fátima, Ribeirão Preto.

"A inteligência do idoso" e "Problemas psicológicos do idoso" (1991). Ciclo de Conferências, Pastoral da 3a Idade, Igreja S. José, maio 1991.

"A inteligência do idoso" (1991). SESC e Igreja S. José, out. 1991.

Conferência: A Situação da Psicologia do Trânsito no Brasil (1990) para pesquisadores do Traffic Research Centre, Haren, Holanda, Univ. Groningen, 12/01/1990.
Curso no Programa de Engenharia de Tráfego - Escola Politécnica - USP

Disciplinas: O fator humano no trânsito (1989); A psicologia aplicada ao tráfego (1990-91); A psicopedagogia do trânsito (1992).

A Psicologia do Trânsito e o idoso (1991). SESC, Esc, Aberta da 3a Idade, Rib. Preto: 09/11/1991.

Segurança no Trânsito (1987). VII SIPAT, IPENCHEN USP, Cidade Universitária, S.Paulo Psicologia do Trânsito EBP (1987). Curso de Graduação e pós-graduação em Química, Instituto de Química USP, S. Paulo e Araraquara.

A situação da Ergonomia no Brasil e na América Latina (1987). I Congresso Latino-Americano e III Seminário Brasileiro de Ergonomia, Convenções Rebouças, S.Paulo, ABERGO.

\section{Resumos Simples em Anais de Eventos}

O uso de computador em psicologia experimental humana - Teoria Soar de Newell e sua aplicação ao trânsito (1994). In: XXIV Reunião Anual de Psicologia da SBP, Ribeirão Preto.

The overtaking ilusions; Why so many people die by overtaking? (1994). In: $13^{\mathrm{TH}}$ World Congress of the International Association for Accident and Traffic Medicine, ABRAMET, São Paulo, SP.

Traffic signs: what do you have to know, their names or your behaviour suggest? (1994). In: $13^{\mathrm{TH}}$ World Congress of the International Association for Accident and Traffic Medicine, ABRAMET, São Paulo, SP.

Curso de psicologia da terceira idade II: aprendizagem e memória (1993). In: XXIII Reunião Anual de Psicologia SBP, Ribeirão Preto.

Algumas pesquisas educacionais de trânsito fora do Brasil (1992). In: XXII Reunião Anual de Psicologia SBP - Anais, Ribeirão Preto, Mesa Redonda, Anais, p. 425-427.

Sinais de Trânsito e Comportamento: Engenharia e Psicopedagogia (1992). In: Anais: VI ANPET, Vol. I, 211221 Rio de Janeiro.

Curso de Psicologia da Terceira Idade I (1991). In: XX Reunião Anual de Psicologia SBPR - Anais, Ribeirão Preto, SP.

A Psicologia Ecológica: O Quê É / Para Quê Serve? (1990). In: XX Reunião Anual de Psicologia, SPRP - Anais, Ribeirão Preto, SP, pp. 49-52

Avaliação do conhecimento de risco da sinalização do trânsito (1988). In: I Congresso Internacional de Segurança de Trânsito, Uberlândia, MG.

The inverted absolute oppel-kundt illusion (1976). In: XXI Congres Internacional de Psychologie, Paris.

Punição e estímulos discriminativos em pombos (1972). In: II Reunião Anual de Psicologia, SPRP, Ribeirão Preto. 


\section{Artigos Completos Publicados em Periódicos}

Silva, Veraneide Araújo da; co-autoria. Os sinais de trânsito: saber os nomes ou saber o quê fazer? (1993). Paradigma, 7 (1), 65-85.

Günther,H; co-autoria. Psicologia ambiental: algumas considerações sobre área de pesquisa e ensino (1993). Psicologia: Teoria e Pesquisa, 9 (1),107-122.

A inteligência do idoso e o trabalho: desfazendo mitos (1992). Participação de Mesa Redonda no Simpósio "População Idosa no Brasil - perspectivas e prioridades das políticas governamentais e comunitárias" I Seminário Nacional de Especialistas Multidisciplinares em Terceira Idade: 24-27/03/1992, Anais. Fundação João Pinheiro, Belo Horizonte, Anais pp. 293-310.

Cem anos de principles of psycology e cem anos de atraso. In: XX Reunião de Psicologia da SPRP - Anais, Ribeirão Preto, SP, 1990 pp. 2-8.

Pottier, Annick; co-autoria; Educational Levels and Field-Dependent/Field-Independent Perceptual Style (1988). Bulletin of the Psychonomic Society, 26 (2), 212-213.

O envelhecimento: 0 idoso, suas capacidades psíquicas e o trabalho (1988). Ciência e Cultura, 40 (7) 673-679.

Informações sobre as pesquisas psico-ergonômicas industriais do INRS (1987). Institut National de Recherches de Sécurité, Psicologia e Trânsito, 3 (1), 101-106.

Estudo comparativo das diversas medidas de dependência/independência do campo e sua relação com a percepção de situações do trânsito (1985). Psicologia e Trânsito, 2 (2), 67-74.

A relação da Psicologia do Trânsito com outras áreas da Psicologia (1985). Psicologia e Trânsito, 2 (2), 53-64.

O exame psicológico para motoristas em alguns países fora do Brasil (1985). Psicologia e Trânsito, 2 (2), 67-74.

O exame psicológico para motoristas em alguns países fora do Brasil (1984). Psicologia e Trânsito, 1 (2), 57- 66,

A opinião de psicólogos brasileiros sobre o exame psicológico para motoristas (1983)._Psicologia e Trânsito, 1 (1), 72-86.

A Psicologia do Trânsito: sua definição e área de ação (1983). Psicologia e Trânsito, 1 (1), 6-19.

A dependência/independência do campo e o comportamento do motorista em situações específicas do trânsito (1982). Arquivos Brasileiros de Psicologia, 34 (2), 28-43.

Style perceptif et conduite automobile (1982). Le Travail Humain, 45 (1), 141-154.

Les mouvements des yeux et les mesures de dependance/ independence du champ (1981). l'Année Psycologique, 81 (1), 511-534.

Estilo perceptivo e acidentes de trânsito (1981). Arquivos Brasileiros de Psicologia, 33 (3), 3-19.

Psicologia do Trânsito: o que é e para que serve (1981). Psicologia: Ciência e Profissão, 1 (1), 141-144.

Silva, José Aparecido da, co-autoria (1979). Erros perceptivos: sua influência no processo de ultrapassagem de veículos. Ciência e Cultura, 30 (5), 587-591.
Silva, José Aparecido da, co-autoria (1979). Construção de uma escala subjetiva de distância pelo método de fracionamento. Psicologia, 5 (1), 45-58.

A avaliação de ângulos iguais e ângulos subjetivamente equivalentes em campo aberto (1977). Estudos Cognitivos, 2 (1), 5-11.

Dois estudos experimentais sobre a percepção visual humana no laboratório e no campo aberto (1977). Arquivos Brasileiros de Psicologia, 29 (1), 95 -165.

A reestruturação do currículo do curso de graduação em Psicologia: uma aplicação da Psicologia Instrucional (1976). Arquivos Brasileiros de Psicologia 28 (1), 78-104.

Dicotomias e tricotomias perceptivas no laboratório (1976). Estudos Cognitivos 1 (1), 5-16.

Battro, Antonio Maria; Pierro Netto, S., coautoria. Riemannian geometries of variable curvature in visual space; Visual alleys, horopters and triangles in big open fields (1976). Perception 5, 9-23.

The inverted absolute oppel-kundt ilusion (1976). Estudos Cognitivos 1 (1), 51 -78.

Alguns efeitos da percepção de distâncias em campo aberto sobre o operador humano (1975). Arquivos Brasileiros de Psicologia Aplicada, 27 (1), 124-132.

\section{Livros Publicados}

Dotta, Attico. Co-autoria. Os sinais de trânsito e o comportamento seguro (1994). Porto Alegre, SAGRA - DC LUCCATTO (2a Edição 1996), 104 p.

Psicologia do Trânsito: conceitos e processos básicos (1988). São Paulo, EPU-EDUSP, 154 p.

Guia internacional de pesquisas em Psicologia do Trânsito (1983). Uberlândia, UFU, 227 p.

Anais: organização e edição dos Anais do III Congresso Brasileiro de Psicologia do Trânsito de 17-19/07/1985 Editora Universidade Federal de Uberlândia, junho de 1986.

Anais: organização e edição dos Anais da XX Reunião Anual de Psicologia da SPRP e resumos, 1990.

Organização e edição da revista "Psicologia e Trânsito" números 1 e 2, (1984) Edit. Universidade Federal de Uberlândia, UFU.

Organização e edição dos Cadernos Brasileiros de Ergonomia, No 1 (1987) Incluindo Anais da 1a Reunião Anual de ABERGO-SBPC - Curitiba, Ed. S. Paulo.

\section{Capítulos de Livros Publicados}

Capítulo: "Envelhecimento, mobilidade e participação no trânsito" (1993). In: A. L. Neri, (Org.). Qualidade de vida e idade madura. Campinas, pp. 157-189.

Capítulo: "Aprendizagem e comportamento no trânsito" (1987). Cap. 7 In: G. Porto Witter e J. F. Lomônaco (Org.) Psicologia da Aprendizagem, Áreas de aplicação, S.Paulo, EPU, pp. 87-124. 


\section{Títulos Honoríficos}

- Atribuição do título de "Sócio Honorário" da SBP, 21/11/1991.

- Homenagem aos melhores trabalhos técnicos, 10 lugar na área de Psicologia e Sociologia do Trânsito, I Congresso Nacional de Segurança Viária, DERSA, 05/ 1989.

- Homenagem do I Congresso Internacional de Psicologia do Trânsito, Uberlândia, 08/1988.

- Medalha "Centenário da Psicologia Científica", pelo Conselho Regional de Psicologia 06/82 São Paulo.

- Eleito e empossado como membro da Academia Paulista de Psicologia, cadeira 34 São Paulo, 14/06/1982.

- Prêmio Emílio Mira e Lopez, pela Monografia: "Dois estudos experimentais sobre a Percepção Visual humana no laboratório e no campo aberto”, ISOP, Rio de Janeiro, 10/ 1976.

t Reinier Johannes Antonius Rozestraten - Um dos pioneiros da psicologia brasileira. Doutor em Psicologia. Era Professor do Mestrado em Psicologia da Universidade Católica Dom Bosco (UCDB - Campo, MS).

Josemar de Campos Maciel - Doutor em Psicologia, Professor do Mestrado em Desenvolvimento Local da Universidade Católica Dom Bosco (UCDB - Campo, MS).

Denise Fernándes Vasconcellos - Artista Plástica e Acadêmica do Curso de Psicologia da Universidade Católica Dom Bosco (UCDB Campo, MS).

Recebido em 20.06.08

Aceito em 12.07.08 